\title{
Clinicopathological Study of Salivary Gland Tumors
}

\author{
Somnath Sangram Khedkar ${ }^{1}$, Anup Pravin Bhandari ${ }^{1 *}$ and Nilesh Pradip Shirgaonkar ${ }^{2}$ \\ ${ }^{1}$ Department of Pathology, BJGMC, Pune, Maharashtra, India. \\ ${ }^{2}$ Department of Pathology, RCSMGMC, Kolhapur, Maharshtra, India.
}

\begin{abstract}
Background: Salivary gland tumors represent the most complex and diverse group of tumors, diagnosis and management of which is complicated by their relative infrequency, the limited amount of pretreatment information available and the wide range of biologic behavior seen with the different pathologic lesions. However, there are no reliable criteria to differentiate, on clinical grounds the benign from the malignant lesions and morphologic evaluation is necessary.

Hence, the present study is undertaken to study the spectrum of benign and malignant tumors of salivary gland with emphasis on histopathological features.

Methods: Prospective and retrospective study (2012 to 2016) comprised of Fine needle aspiration cytology (FNAC), histopathology specimens and slides received in our Department of Pathology during period of 5 years. In each patient age, sex, site and relevant clinical details were recorded in a proforma. FNAC is performed whenever possible followed by histopathological examination as gold standard for diagnosis. Results were analysed in tabular format and Sensitivity, Specificity and Diagnostic accuracy were calculated according to standard formulas.

Result: During the study period of five years 60 salivary gland neoplasms were studied out of which 40 were benign, most common being pleomorphic adenoma. Most common malignant tumor was mucoepidermoid carcinoma. Mean age of presentation was 41 years. Histocytological correlation was obtained in 40 cases.

Conclusion: Salivary gland tumors are relatively uncommon, and exhibit a wide variety of microscopic appearances, even within one particular lesion, and this has caused considerable problems in categorization and diagnosis. Accurate diagnosis is essential as salivary gland neoplasms have diverse clinical and prognostic outcomes.
\end{abstract}

Keywords: Salivary Gland Tumors, Fine Needle Aspiration Cytology, Histopathology, Pleomorphic Adenoma, Mucoepidermoid Carcinoma.

\section{Introduction}

Salivary gland tumors represent the most complex and diverse group of tumors encountered by the head and neck oncologist. Their diagnosis and management is complicated by their relative infrequency, the limited amount of pretreatment information available and the wide range of biologic behavior seen with the different pathologic lesions.

Salivary gland tumors can arise from either the major salivary glands (parotid, submandibular and sublingual) or the minor salivary glands which are located throughout the sub mucosa of the upper aero digestive tract. They can show a striking range of morphological diversity between different tumor types and sometimes within an individual tumor mass. In addition, hybrid tumors, dedifferentiation and the propensity for some benign tumors to progress to malignancy can confound histopathological interpretation. ${ }^{[1,2]}$ However, there are no reliable criteria to differentiate, on clinical grounds the benign from the malignant lesions and morphologic evaluation is necessary. ${ }^{[3]}$ Hence, the present study is undertaken to study the spectrum of benign and malignant tumors of salivary gland with emphasis on histopathological features. Also, an effort is made for histocytological correlation wherever possible.

Salivary gland tumors comprise $3-6 \%$ of all head and neck neoplasms in adults with the incidence being one to three per 1,00,000 people per year. The mean age at presentation for malignant salivary neoplasms is 55 to 65 years while benign lesions typically develop atleast a decade earlier, at a mean age of 45 years. ${ }^{[2]}$ The parotid gland is the most common location of salivary gland tumors which accounts for $70-85 \%$ cases. Other sites include the submandibular gland $(8-15 \%)$ the sublingual gland $(<1 \%)$ and the minor salivary glands, which are most densely concentrated in the hard palate (6-8\%), but present throughout the upper aerodegestive tract.

As a general of rule, the smaller the salivary gland in adults, the higher the probability that a neoplasm arising in such 
a gland will be malignant. Malignant tumors comprise 15$25 \%$ of all parotid tumors, $37-43 \%$ of submandibular gland tumors and over $80 \%$ of minor salivary gland tumors. ${ }^{[3]}$

\section{Materials and Methods}

The present clinicopathological study of salivary gland tumors is a both prospective (from 2014 to 2016) and retrospective study (from 2012 to 2014). The material for the study comprised of histopathology specimens, blocks and slides received in Department of Pathology in our Hospital during this period of 5 years.

The specimens consisted of biopsies, partially resected and completely excised salivary gland lesions with or without the draining lymph nodes of that region. Cytology specimen consists of aspiration procedure as well as directly sent slides for study. Retrospective study was done using histopathology as well as cytology slides review from archives of particular cases. Clinical history and findings were recorded in each case by complete clinical examination and from case records. In each patient age, sex, site, presenting symptoms and relevant clinical details were recorded in a proforma. ${ }^{[4]}$

The specimens were fixed in $10 \%$ neutral buffered formalin for 24 to 48 hours. Large specimens were cut serially at a distance of 1 centimeter before fixing.

After fixation, representative areas were selected for paraffin embedding, including the tumor proper and the margin of the tumor with surrounding tissue. Four to five paraffin blocks of each specimen were prepared and sections of 3-5 microns thickness were cut and stained with hematoxylin and eosin. Microscopic examination of the stained sections was performed. Special stains like PAS with or without diastase, and mucicarmine were performed when necessary. ${ }^{[5,6]}$

The tumors were classified employing the new WHO international classification as a guideline..$^{[2]}$

Histocytological correlation was done wherever possible. Cytological diagnosis was correlated with histopathological diagnosis. Histopathology diagnosis is considered as a gold standard.

Previously we wanted to study cytological features of every case in detail along with histopathology but due to reasons like non availability of previous cytological records, damaged and poor quality of slides in view of retrospective cases, we have just only correlated available cytological diagnosis with histopathological diagnosis in these cases. We have not included detailed cytological study of every case. Else we have done this clinicopathological study of salivary gland tumors with emphasis on histopathological features of every case. Sensitivity, Specificity and
Diagnostic accuracy were calculated according to standard formulas manually.

\section{Result}

Out of 60 salivary gland tumors studied during the five year period - 40 were benign and 20 were malignant. Prevalence of salivary gland tumors in our study was $0.28 \%$. (The total number of biopsies received during the five year period was 20,860 ).

In the present study, the salivary gland neoplasms presented over a wide range of age from 16 years to 72 years. The mean age was 40.95 years. Majority of the tumors in this study occurred between the ages of 20 to 60 years. Most of the benign neoplasms occurred between the ages of 20 and 60 years. Majority of the malignant neoplasms occurred between the ages of 30 and 60 years. Mean age for benign neoplasms was 39.36 years and mean age for malignant neoplasms was 44.42 years.

The overall sex incidence of salivary gland tumors in males was $51.66 \%$ and $49.34 \%$ in females with a male to female ratio of 1.06:1. Male to Female ratio for benign tumors was 1:1 and for malignant tumors it was 1.22:1. Among the benign tumors, female preponderance was seen in pleomorphic adenoma. Other benign tumors occurred in males only. Among malignant tumors mucoepidermoid carcinoma, polymorphous low grade adenocarcinoma and adenocarcinoma not otherwise specified showed male preponderance, whereas others showed a female preponderance.

Most of the tumors were located in the major salivary gland (95\%) among which parotid was the commonest site $(88.47 \%)$. Minor salivary glands were involved in $5 \%$ of cases which were all malignant. (Table 1)

All the 60 patients in our study presented with mass $(100 \%)$. Pain and tenderness $(20 \%)$, rapid enlargement of the mass $(10 \%)$, palpable cervical lymph nodes $(5 \%)$, No facial paralysis was seen in our study.

Histocytological correlation was done in 40 cases only, where proper cytological and histopathological features were studied and both conclusive cytological and histopathological diagnosis were obtained. Cytological diagnosis was compared with histopathological diagnosis (Table 2). Histopathological diagnosis is used as a gold standard. Rests of the aspirates were scanty, hemorrhagic or non diagnostic. Only one case was falsely diagnosed as Pleomorphic adenoma on cytology (false positive) but on histopathology it came out as mucoepidermoid carcinoma. Overall Sensitivity, Specificity and Diagnostic accuracy of the Cytological study were 97.5\%, 99.16 and $98.8 \%$ respectively. 
Table 1: Percentage Distribution of Different Types Of Tumors.

\begin{tabular}{|c|c|c|c|c|c|c|c|}
\hline \multirow{2}{*}{$\begin{array}{l}\text { Category } \\
\text { of tumor }\end{array}$} & \multirow{2}{*}{$\begin{array}{l}\text { Histopathological } \\
\text { Type of tumor }\end{array}$} & \multirow{2}{*}{$\begin{array}{l}\text { No. of cases } \\
\text { (M/F) }\end{array}$} & \multirow[t]{2}{*}{ Percentage } & \multicolumn{4}{|c|}{ Site of tumor } \\
\hline & & & & Parotid & Submandibular & Sublingual & Minor salivary \\
\hline \multirow[t]{4}{*}{$\begin{array}{l}\text { Benign } \\
(40)\end{array}$} & $\begin{array}{l}\text { Pleomorphic } \\
\text { adenoma }\end{array}$ & $35(15 / 20)$ & $58.33 \%$ & 33 & 2 & 0 & 0 \\
\hline & Warthin tumor & $3(3 / 0)$ & $5 \%$ & 3 & 0 & 0 & 0 \\
\hline & $\begin{array}{l}\text { Basal cell } \\
\text { adenoma }\end{array}$ & $1(1 / 0)$ & $1.66 \%$ & 1 & 0 & 0 & 0 \\
\hline & Myoepithelioma & $1(1 / 0)$ & $1.66 \%$ & 0 & 1 & 0 & 0 \\
\hline \multirow[t]{6}{*}{$\begin{array}{l}\text { Malignant } \\
(20)\end{array}$} & $\begin{array}{l}\text { Mucoepidermoid } \\
\text { carcinoma }\end{array}$ & $14(8 / 6)$ & $23.33 \%$ & 12 & 1 & 0 & 1 \\
\hline & $\begin{array}{l}\text { Adenoid cystic } \\
\text { carcinoma }\end{array}$ & $3(2 / 1)$ & $5 \%$ & 2 & 1 & 0 & 0 \\
\hline & $\begin{array}{l}\text { Acinic cell } \\
\text { carcinoma }\end{array}$ & $1(1 / 0)$ & $1.66 \%$ & 0 & 0 & 1 & 0 \\
\hline & $\begin{array}{l}\text { Polymorphous } \\
\text { low grade } \\
\text { adenocarcinoma }\end{array}$ & $1(0 / 1)$ & $1.66 \%$ & 0 & 0 & 0 & 1 \\
\hline & $\begin{array}{l}\text { Adenocarcinoma } \\
\text { not otherwise } \\
\text { specified }\end{array}$ & $1(0 / 1)$ & $1.66 \%$ & 0 & 0 & 0 & 1 \\
\hline & Total & 60 & $100 \%$ & 51 & 5 & 1 & 3 \\
\hline
\end{tabular}

Table 2: Histocytological Correlation.

\begin{tabular}{|l|l|l|l|}
\hline Cytological Diagnosis & \multirow{2}{*}{ No. of cases } & \multicolumn{2}{l|}{ Histopathological correlation } \\
\cline { 3 - 5 } & & Compatible & Non compatible \\
\hline Pleomorphic Adenoma & 31 & 30 & 1 \\
\hline Warthins tumor & 1 & 1 & 0 \\
\hline Mucoepidermoid carcinoma & 7 & 7 & 0 \\
\hline Adenoid cystic carcinoma & 1 & 1 & 0 \\
\hline Total & $\mathbf{4 0}$ & $\mathbf{3 9}$ & $\mathbf{1}$ \\
\hline
\end{tabular}

Table 3: Comparative study.

\begin{tabular}{|c|c|c|}
\hline Parameters & Our Study (values in percentage) & Other studies (values in percentage) \\
\hline Prevalence of salivary gland tumors & 0.28 & $\begin{array}{l}\text { Solange et al[11] } \\
1.50\end{array}$ \\
\hline $\begin{array}{l}\text { Frequency of benign and malignant } \\
\text { neoplasms }\end{array}$ & Benign/Malignant- 66.66/ 33.33 & $\begin{array}{l}\text { Gupta et } \mathrm{al}^{\left[\left[^{12]}\right]\right.} \\
69.90 / 30.10\end{array}$ \\
\hline Age of Salivary Gland Neoplasms & Benign/Malignant- 39.36/42.42 & $\begin{array}{l}\text { Thomas et al }{ }^{[13]} \\
39 / 46\end{array}$ \\
\hline Site of neoplasm & $\begin{array}{l}\text { Parotid/ Submandibular /Sublingual/ } \\
\text { Minor- 88.33/5/1.66/ } 5\end{array}$ & $\begin{array}{l}\text { Davies et al[14] } \\
75.0 / 13.7 /-/ 11.30\end{array}$ \\
\hline Histocytological correlation & Diagnostic accuracy -98.80 & $\begin{array}{l}\text { Qizilbash }{ }^{[15]} \\
98\end{array}$ \\
\hline Sensitivity and specificity of FNAC & Sensitivity - 97.5 Specificity - 99.16 & $\begin{array}{l}\text { Ersoz C et al[16] Sensitivity }-94.0 \\
\text { Specificity - } 100\end{array}$ \\
\hline
\end{tabular}




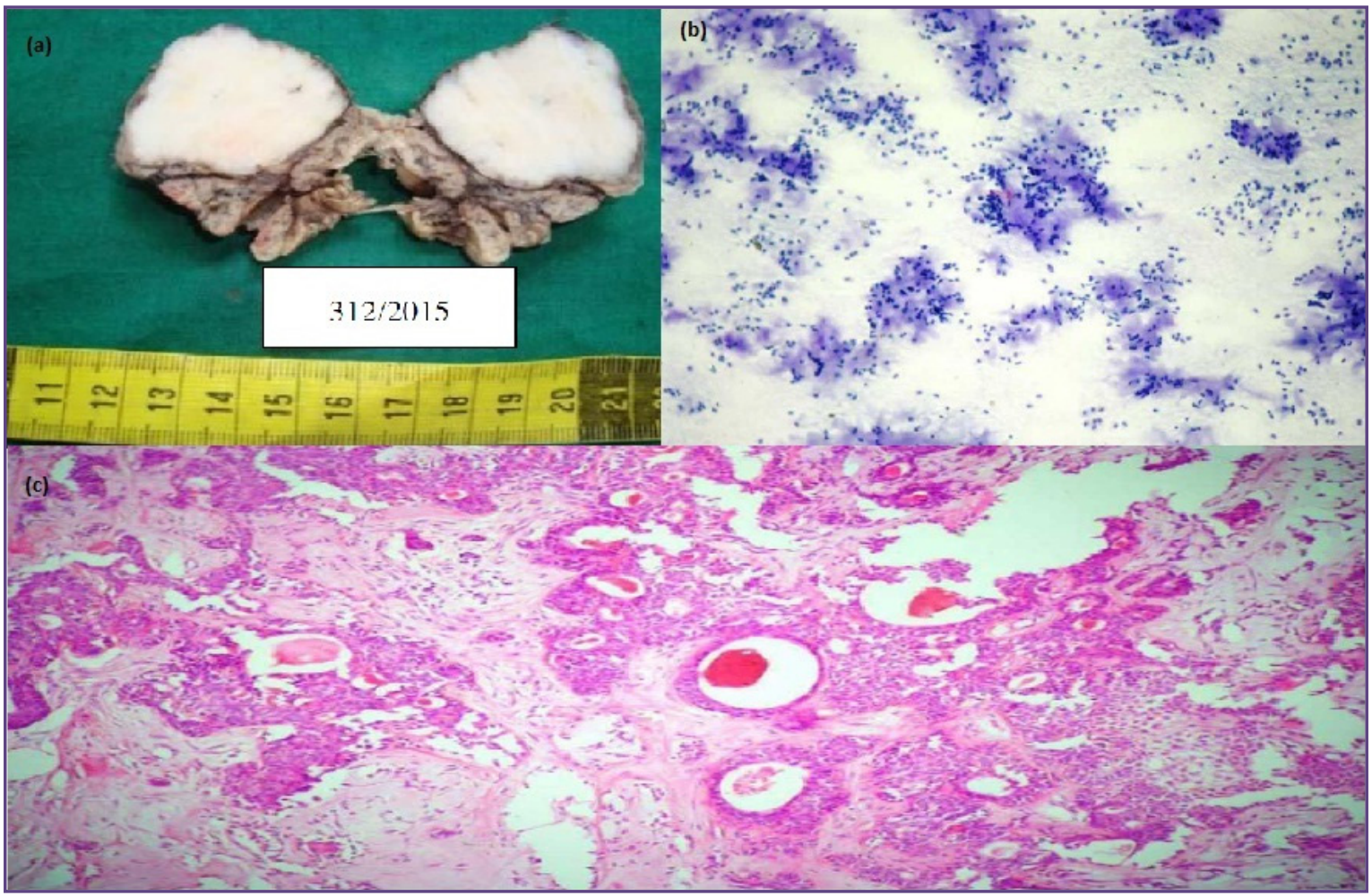

Fig. 1: Pleomorphic adenoma. (a)Gross features (b) cytology 10X-Leishman stain (c) Histopathology- H\&E stain.

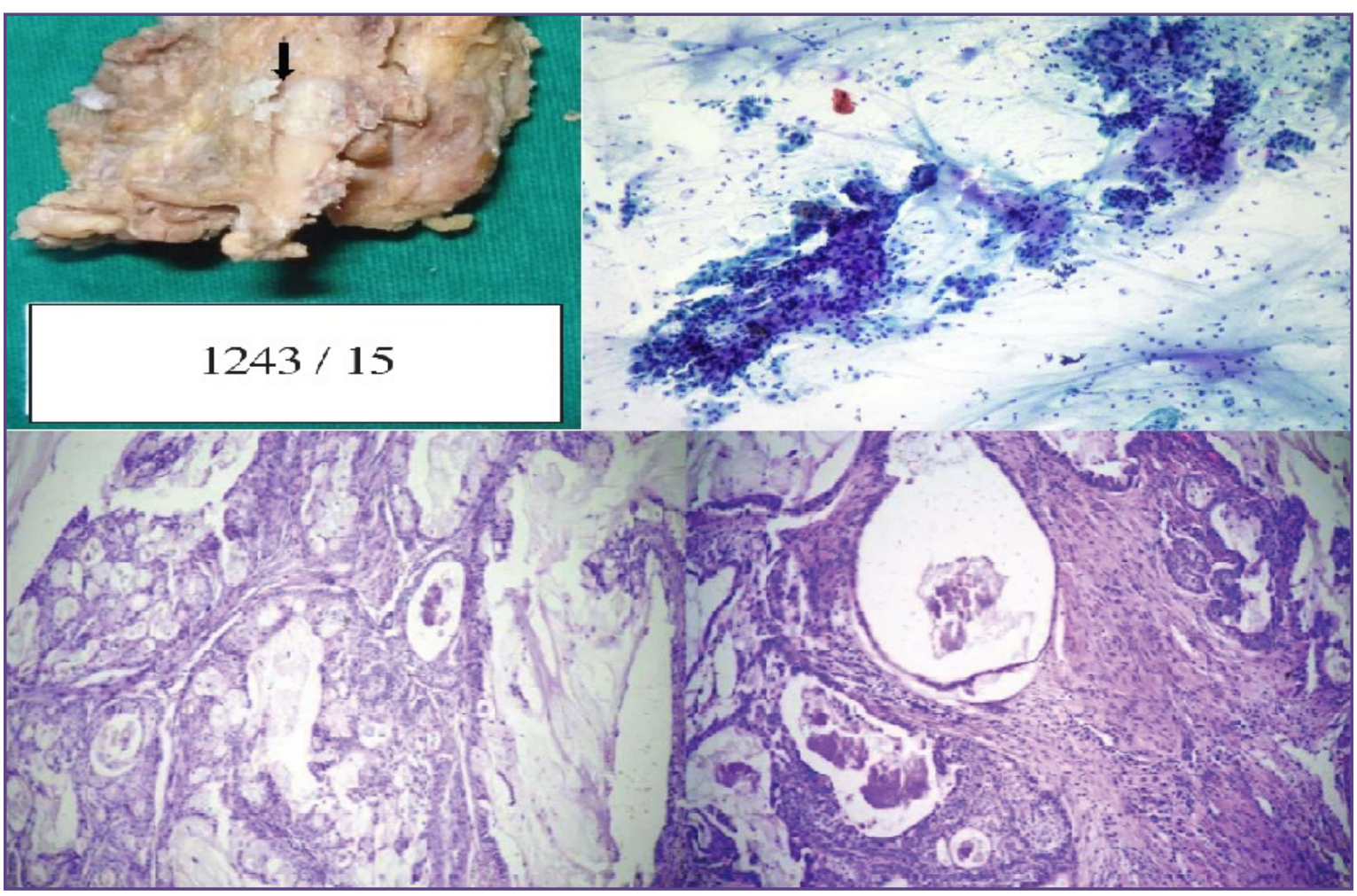

Fig. 2: Mucoepidermoid carcinoma. (a)Gross features (b) cytology 10X-Leishman stain (c\&d) Histopathology- H\&E stain. 


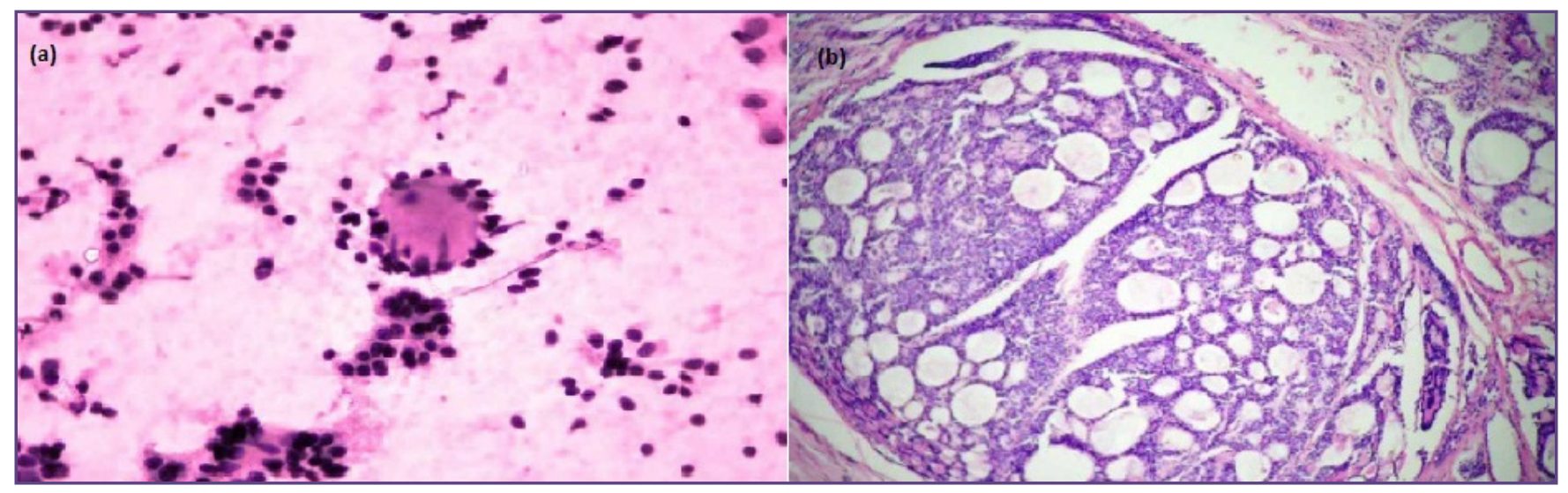

Fig. 3: Adenoid cystic carcinoma. (a) cytology 10X-Leishman stain (b) Histopathology- H\&E stain.

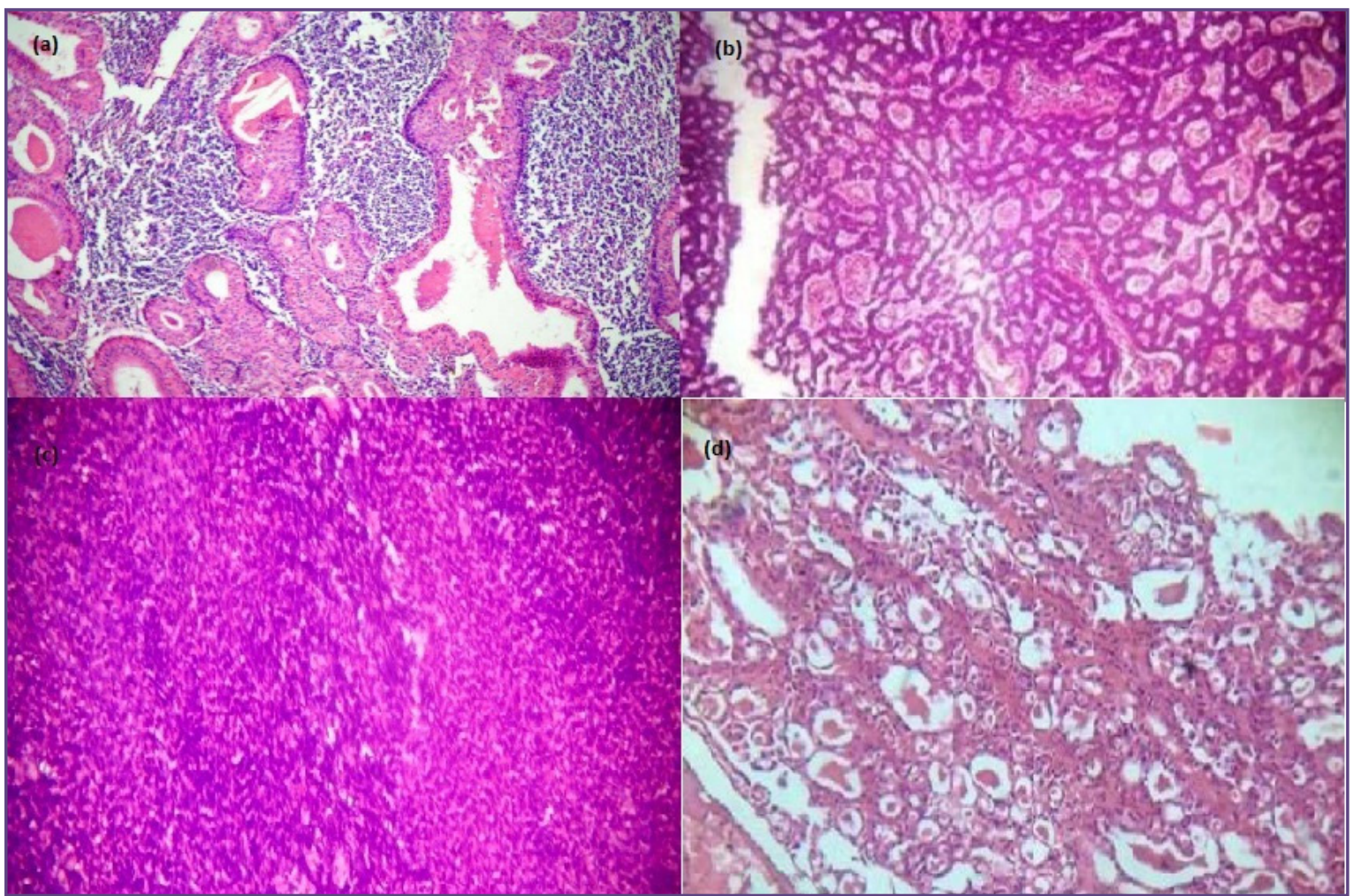

Fig. 4: Characteristic histological features- H\&E stain (a) Warthin's tumor (b) Basal cell adenoma (c) Myoepithelioma (d) Polymorphous low grade adenocarcinoma.

\section{Discussion}

Prevalence of salivary gland tumors in our study was 0.28 $\%$ which is very uncommon occurrence as is comparable with Araya $\mathrm{J}$ et al. ${ }^{[7]}$ The salivary gland neoplasms presented over a wide range of age from 18 years to 69 years. The mean age was 41 years. Most of the benign neoplasm occurred between the ages of 20 and 50 years (mean age40.18 years). Majority of the malignant neoplasms also occurred between the ages of 30 and 60 years (mean age46.54 years).
The overall sex incidence of salivary gland tumors in males was $51.66 \%$ and $49.34 \%$ in females with a male to female ratio of $1.06: 1$. Male:Female ratio for benign tumors was 1:1 and for malignant tumors it was 1.2:1. Female preponderance was seen in pleomorphic adenoma. Other benign tumors occurred in males only. All these epidemiological findings are comparable with many other studies. ${ }^{[7-10]}$

Most of the tumors were located in the major salivary glands (95\%) among which parotid was the commonest 
site $(87.5 \%)$. Minor salivary glands were involved involved in $5 \%$ of cases. All the cases in our study presented with mass. In addition to it pain was observed in 10 cases which include all cases of adenoid cystic carcinoma. Palpable cervical lymph nodes were seen in 3 cases. No cases presented with facial palsy in our study. These findings were comparable with different other studies as mentioned in Table 3.

During the study period of five years 60 salivary gland neoplasms were studied. Out of this 40 were benign tumors and 20 were malignant tumors on histopathology. Pleomorphic adenoma was the commonest benign neoplasm accounted for $87.5 \%$ of all benign neoplasms. Most common site for involvement was parotid gland. Histomorphology of the pleomorphic adenoma revealed classical features. Chondromyxoid stroma was the commonest stromal component followed by myxoid and hyaline stroma. Most of them showed the melting phenomenon at least focally. One case showed areas of calcification. One case showed focal squamous metaplasia. All cases show thin capsule grossly atleast focally. In 30 cases histocytological correlation was obtained(Fig 1).

Out of 20 malignant neoplasms, mucoepidermoid carcinoma accounted for $70 \%$ of all malignant neoplasms most common site being parotid followed by palate. Grossly, most of tumors show cystic spaces with areas of necrosis and haemorrhages. Tumors with florid lymphoid reaction can be mistaken for Warthin tumor, where assessment of borders and lining epithelium is necessary. Two cases of intermediate grade tumors showed perineural invasion. Single lymph node metastasis was seen in a case of intermediate grade tumor and one case of high grade tumor(Fig 2). No secondaries in salivary glands were encountered in our study. In 7 cases histocytological correlation was obtained, while one case was wrongly diagnosed as pleomorphic adenoma cytologically.

Adenoid cystic carcinoma in our study showed male preponderance with all three cases occurring in major salivary glands. Microscopically, all showed infiltrative cribriform pattern of basaloid cells with 2 cases showing perineural invasion(Fig 3). Cytohistological correlation was hundred percent.

Three cases of Warthin tumors were seen in our study, all of them occurred in elderly males and showed characteristic bilayered oncocytic epithelium lining the cystic spaces with underlying lymphoid follicles. One case of Warthin's tumor diagnosed on cytology was also correlated correctly on histopathology (Fig 4).

One case each of Basal cell adenoma, Myoepithelioma, Acinic cell carcinoma and Polymorphous low grade adenocarcinoma were seen in our study with characteristic histopathological findings (Fig 4). It is important to differentiate polymorphous low grade adenocarcinoma because of their bland looking morphology they can mimic benign tumors. So assessment of borders is critical for identification of these tumors. Our case showed perineural invasion by tumor cells. Similar findings were noted by Nagao T et al. ${ }^{[17]}$

A single case of Adenocarcinoma not otherwise specified was seen affecting the buccal mucosa which showed pleomorphic tumor cells arranged in non specific histologic patterns. Areas of hemorrhage was also seen with high mitotic activity. Similar findings were observed by Seifert et $\mathrm{al}^{[18]}$ but he also reported mucous production in $40 \%$ of his cases, which is not seen in our study.

\section{Conclusion}

Salivary gland tumors are relatively less common, and they exhibit a wide variety of microscopic appearances, even within one particular lesion and this has caused considerable problems in categorization and diagnosis essential for prognostic outcomes. Parotid is most commonly affected salivary gland with pleomorphic adenoma as most common lesion. Mucoepidermoid carcinoma was the commonest malignant tumor observed with predilection for minor salivary glands. As salivary gland lesions always exclusively present with mass, cytology remain good viable option for diagnosis with high sensitivity and specificity.

\section{Acknowledgements}

Department of surgery, BJGMC, Pune

\section{Funding}

Self

\section{Conflict of Interests}

Nil

\section{Reference}

1. Chan JK, Cheuk W. Salivary gland tumors. Chapter 7, In : Fletcher CDM, editor. Diagnostic histopathology of tumors. 3rd ed. china: Churchill Livingstone Elsevier; 2007. p. 239325.

2. Barnes L, Eveson JW, Reuichart P, Sidrawsky D. WHO classification of tumors. Pathology and Genetics of Head and Neck Tumors : Lyon : IARC Press; 2005. p. 209-281.

3. Lingel MW, Kumar V. Head and Neck. Chapter 16, In : Kumar V, Abbas AK, Fausto N, editors. Robbins and Cotran Pathologic basis of disease. 7th ed, Philadelphia : Saunders; 2004. P. 790-91.

4. Sharkey FE. Clinicopathologic study of 366 salivary gland tumors . Am J Clin Pathol 1977;67:272-278.

5. Dardick I. Histogenesis and morphogenesis of salivary gland neoplasms. Chapter 7. In : Ellis GL, Auclair PL, Gnepp DR, 
editors. Surgical pathology of the salivary glands. Vol. 25, Philadelphia : WB Saunders Company; 1991. P.108-129.

6. Cheuk W, Chan JKC. Advances in salivary gland pathology. Histopathology 2007;51: 1-20.

7. Araya J, Martinez R, Niklander S, Marshall M, Esguep A. Incidence and prevalence of salivary gland tumours in Valparaiso, Chile. Med Oral Patol Oral Cir Bucal. 2015;20(5):e532-e539. Published 2015 Sep 1. doi:10.4317/ medoral.20337

8. de Oliveira FA, Duarte EC, Taveira CT, Maximo AA, de Aquino EC, Alencar RC. Salivary gland tumor: a review of 599 cases in a Brazilian population. Head and neck pathology. 2009;3:271-5.

9. Tian Z, Li L, Wang L, Hu Y, Li J. Salivary gland neoplasms in oral and maxillofacial regions: a 23-year retrospective study of 6982 cases in an eastern Chinese population. International journal of oral and maxillofacial surgery. 2010;39:235-42.

10. Lukši? I, Virag M, Manojlovi? S, Macan D. Salivary gland tumours: 25 years of experience from a single institution in Croatia. Journal of cranio-maxillo-facial surgery. 2012;40:e7581.Nagaon, T., Gaffey, T.A., Kay, P.A., Minato, H., Seriawa, H. and Lewis, J. E. (2004), Polymorphous low-grade adenocarcinoma of the major salivary glands: report of three cases in an uhnusual location. Histopathology, 40: 164-171.
11. Solange SL, Andrea FS, Rivadaxia FB, Roseana DA. Epidemiologic profile of salivary gland neoplasms: analysis of 245 cases. Rev Bras Otorhinolaryngo 2005; 71(3): 335340 .

12. Gupta SK, Sengupta P, Sarkar SK. Primary tumors of salivary glands. J Ind Med Assoc 1975;65(10):277-280.

13. Thomas KM, Hutt MSR, Borgstein J. Salivary gland tumors in Malawi.Cancer 1980;46:2328-2334.

14. Davies JNP, Doge OG, Burkitt DP. Salivary gland tumors in Uganda.Cancer 1964;17:1310-1322.

15. Cheuk W, Chan JKC. Advances in salivary gland pathology. Histopathology 2007;51: 1-20.

16. Ersöz, Canan \& Uguz, Aysun \& Tuncer, Ülkü \& Soylu, Levent \& Kiroglu, Mete. (2004). Fine needle aspiration cytology of the salivary glands: a twelve years' experience. Aegean Pathol J. 1.

17. Nagaon, T., Gaffey, T.A., Kay, P.A., Minato, H., Seriawa, H. and Lewis, J. E. (2004), Polymorphous low-grade adenocarcinoma of the major salivary glands: report of three cases in an uhnusual location.Histopathology, 40: 164-171.

18. Seifert G, Schulz J. Adenocarcinoma of the salivary glands. The pathohistology and sub-classification of 77 cases. HNO $1985 ; 33(10): 433-442$.

*Corresponding author:

Dr. Anup Pravin Bhandari, A-304, Dreams Onella, Satavnagar, Handewadi road, Hadapsar, Pune, Maharashtra state. Pin- 411028, INDIA

Phone: +91 8237073073

Email: anupbhandari154@gmail.com

Financial or other Competing Interests: None. 